\title{
鏡面反射光を利用した固体表面速度および 角度のレーザー・ドップラ計測 ${ }^{\dagger}$
}

\author{
岡田英 史*・南 谷 晴 之* \\ Laser Doppler Measurement of Solid Surface Velocity and \\ the Moving Angle by Use of Specular Reflection
}

Eiji OKadA* and Haruyuki Minamitani*

On the measurement of velocity of moving solid surface by using a laser Doppler velocimeter (LDV), diffuse and specular reflection can be observed in the back scattering region. Since the specular reflection (SR) is followed by the law of geometrical optics, direction of the reflected beam changes with the moving angle of solid surface. However, the utilization of SR has never been considered on the LDV measurement.

In this study, we proposed a new differential method of LDV, in which the SR beam was again reflected by means of a mirror (specular re-reflection, SRR) and arranged to enter into the sampling volume as an incident light. As consequence by crossing three laser beams (SR and two inherent incident beams) in the focal point, three different interference were constructed in the sampling volume. When scatters pass through the sampling volume, scattered light emits and involves three different Doppler frequency shifts which give an information regarding the velocity of the solid surface and the moving angle.

In the present paper, theoretical investigation was carried out about the effect of SRR on the Doppler signals correlated with the moving angle of the solid surface. Fundamental experiment was also carried out by using a rotating disk and the results were compared with the theoretical aspects. Application of the Doppler effect caused by SRR

†流れの計測と可視化 大阪ジョイント講演会で一部発 表 (昭 $60 \cdot 10$ )

* 慶応義塾大学理工学部 横浜市港北区日吉 3-14-1

* Faculty of Science and Technology, Keio

University, Yokohama

(Received January 13, 1986)

(Revised May 7, 1986) was additionally discussed.

Key Words: laser Doppler velocimeter, specular reflection, moving solid surface

\section{1. 緒言}

レーザー・ドップラ速度計 (Laser Doppler Velocimeter, 略して LDV) は 2 本のレーザー光を交差さ せることによって测定体積に干渉縞を形成し，そこを 通過する散乱体からの散乱光のドップラ周波数シフト から速度を求める測定法である. そのため非接触測定 が可能である, 測定速度とドップラ周波数の関係が線 形である，応答が速く速度の瞬時值を連続的に测定で きる, 空間分解能がよい, などの利点がある. 反面, 測定対象に光を散乱させる要因が必要であるという測 定条件をむつ.

気体, 液体流の測定のときは散乱体として微粒子を 測定対象に混入することによってドップラ周波数シフ トをうけた散乱光を得る．乙の混入する微粒子の粒子 径や形状と出力されるドップラ信号の特性のあいだに

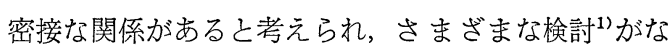
されている.

測定対象が固体表面の場合, 固体表面にレーザー光 を入射するとその表面の粗さに応じて拡散反射と鏡面 反射が一定の比率で生じる ${ }^{2)}$. このうち拡散反射によ る散乱光は流体速度計測における散乱粒子からの散乱 光と同様に固体表面の速度に応じたドップラ周波数シ フトをうけており，測定対象の速度に関する情報をむ っている．また鏡面反射によるビーム状の反射光は幾 何光学的に反射の法則にしたがっているので固体表面 の移動方向に関する情報をむっている. しかし, 従来 のレーザー・ドップラ速度計測においてての鏡面反射 光の利用についてはほとんど検討がなされていない. 
1102 昭和 61 年 10 月

著者らはこの固体表面からの鏡面反射光の幾何光学 的性質に着目し，鏡面反射光の一方を反射鏡を用いて 再反射させ固体表面上の測定体積に入射させるととに より測定体積に多重干渉縞を形成し，そのとき得られ る複数のドップラ周波数から固体表面の移動方向を求 めて，固体表面の速度を 2 次元速度成分表示する手法 を考案した.

本論文では 2 本の入射光, および固体表面から生じ る鏡面反射光の再反射光の計 3 本のレーザー光で形成 される測定体積から生じる散乱光のドップラ周波数シ フトに関する理論的検討を行う．ついで，回転円盤を 用いた基礎的実験の結果を示し，理論との比較検討を 行い，再反射光に依存するドップラ周波数の特性とそ の利用法について述べる.

\section{2. 記 号一覧}

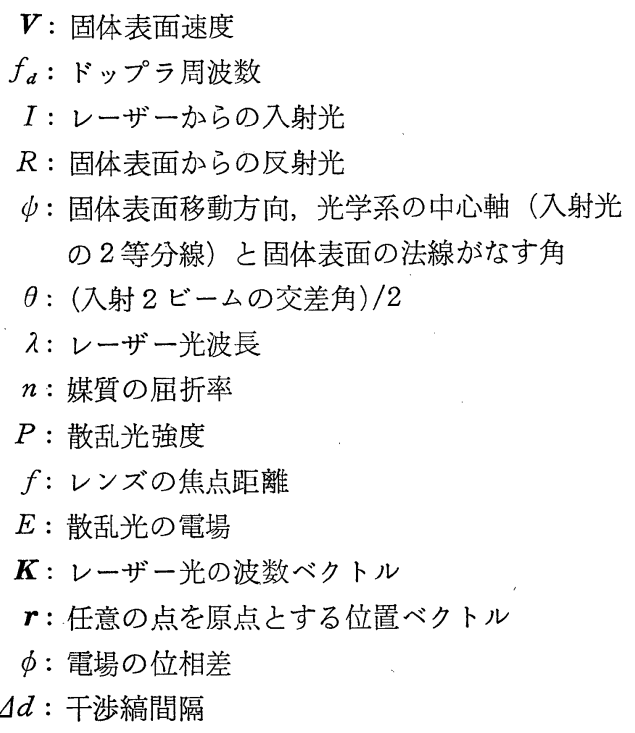

\section{3. 原理}

レーザー・ドップラ速度計による固体表面速度測定 の原理を Fig. 1 亿示す.とれは干涉縞法という手法 で 2 本のレーザー光 $I_{1}, I_{2}$ (波数ベクトル $\boldsymbol{K}_{1}, \boldsymbol{K}_{2}$ ) を固体表面上で交差させ測定体積を形成する．乙のと き，固体表面の凹凸による拡散反射にって生じた 2 本のレーザー光からの散乱光は観測方向 $\left(\boldsymbol{K}_{s}\right)$ では固 体表面の速度 $\boldsymbol{V}$ に応じた量だけドップラ周波数シフ トを受けており，ての二つの散乱光をレンズで重ね合 せてビートをフォトマルで観測する．2 本のレーザー 光 $I_{1}, I_{2}$ による観測方向 $\boldsymbol{K}_{s}$ に対する散乱光の電場 $E_{1}, E_{2}$ は次式のように表わされる3゙.

$$
E_{1}=A_{1} \exp \left[-i\left\{\omega t+\left(\boldsymbol{K}_{s}-\boldsymbol{K}_{1}\right) \cdot \boldsymbol{V} t-\boldsymbol{K}_{s} \cdot \boldsymbol{r}\right\}\right]
$$

第 22 巻 第 10 号

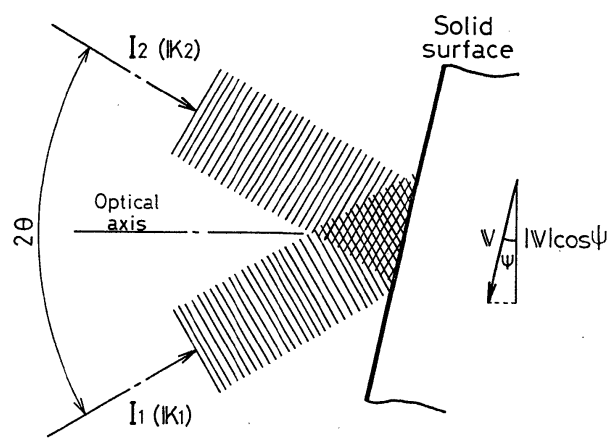

Fig. 1 Principle of measuring the velocity of solid surface by means of laser Doppler velocimeter

$E_{2}=A_{2} \exp \left[-i\left\{\omega t+\left(\boldsymbol{K}_{s}-\boldsymbol{K}_{2}\right) \cdot \boldsymbol{V} t-\boldsymbol{K}_{s} \cdot \boldsymbol{r}+\phi_{1}\right\}\right]$

(1. b )

よって, フォトマルで観測される強度 $P$ は

$$
\begin{aligned}
& P \propto\left(E_{1}+E_{2}\right)\left(E_{1}^{*}+E_{2}^{*}\right) \\
& \quad=A_{1}{ }^{2}+A_{2}{ }^{2}+2 A_{1} A_{2} \cos \left\{\left(\boldsymbol{K}_{2}-\boldsymbol{K}_{1}\right) \cdot \boldsymbol{V} t+\phi_{1}\right\}
\end{aligned}
$$

となる. こてで $A_{1}{ }^{2}+A_{2}{ }^{2}$ は直流成分で, 最後の項か らドップラ周波数 $f_{d}$ が測定できる.すなわち，

$$
f_{d}=\frac{\left(\boldsymbol{K}_{2}-\boldsymbol{K}_{1}\right) \cdot \boldsymbol{V}}{2 \pi}=\frac{2 n|\boldsymbol{V}| \cos \phi \sin \theta}{\lambda}
$$

また， 2 本のレーザー光の波面の位相差によって交 差部に生じる干渉縞の間隔は $\lambda / 2 n \sin \theta$ であるので, (3) 式のドップラ周波数は干涉縞の明暗の変化による 散乱光の強度変化の周波数であるという解釈 むでき る.

このとき, 測定されたドップラ周波数 $f_{d}$ から求め られるのは光学系の中心軸に垂直な速度成分 $|\boldsymbol{V}| \cos \psi$ のみで, 固体表面速度 $|\boldsymbol{V}|$ ならびにその移動方向 $\phi$ を独立に求めるためには 2 次元， 3 次元測定が可能な 光学系の構成が必要となる.

固体表面での鏡面反射によって生ずる反射光 $R_{1}$, $R_{2}$ は幾何光学的な反射の法則にしたがうので，乙れ らが $I_{1} ， I_{2}$ となす角は，Fig. 2 亿示すように固体表 面の移動方向 $\psi$ に依存している. この鏡面反射光加ら 固体表面の移動方向に関する情報を得るため, こてで は 2 本の鏡面反射光のうち $R_{1}$ のみ反射鏡を用いて測 定体皘侢入射させるあのとする.

このとき, 測定体積は等価的に 3 本の入射光によっ て形成されると考えることができる，乙てで，鏡面反 射光を利用した 3 本目の入射光 $R_{1}$ (波数べクトル $\boldsymbol{K}_{3}$ ) による観測方向 $\boldsymbol{K}_{s}$ に対する電場 $E_{3}$ は

$$
E_{3}=A_{3} \exp \left[-i\left\{\omega t+\left(\boldsymbol{K}_{s}-\boldsymbol{K}_{3}\right) \cdot \boldsymbol{V} t-\boldsymbol{K}_{s} \cdot \boldsymbol{r}+\phi_{2}\right\}\right]
$$




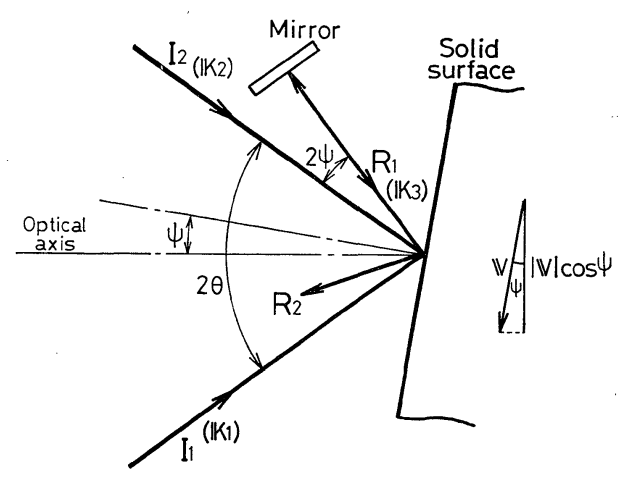

Fig. 2 Optical geometry of incident beams and the specular reflection beams of which direction changes with the measuring angle of solid surface

となる. よって $I_{1}, I_{2}, R_{1}$ の 3 本のレーザー光から の散乱光をフォトマルで観測したときの強度 $P^{\prime}$ は次 式のように表わされる.

$$
\begin{aligned}
P_{\infty}^{\prime} & \left(E_{1}+E_{2}+E_{3}\right)\left(E_{1}^{*}+E_{2}^{*}+E_{3}^{*}\right) \\
= & A_{1}{ }^{2}+A_{2}{ }^{2}+A_{3}{ }^{2}+2 A_{1} A_{2} \cos \left\{\left(\boldsymbol{K}_{2}-\boldsymbol{K}_{1}\right) \cdot \boldsymbol{V} t-\phi_{1}\right\} \\
& +2 A_{2} A_{3} \cos \left\{\left(\boldsymbol{K}_{3}-\boldsymbol{K}_{2}\right) \cdot \boldsymbol{V}_{t}-\left(\phi_{2}-\phi_{1}\right)\right\} \\
& +2 A_{3} A_{1} \cos \left\{\left(\boldsymbol{K}_{1}-\boldsymbol{K}_{3}\right) \cdot \boldsymbol{V} t-\phi_{2}\right\}
\end{aligned}
$$

ここで, $A_{1}{ }^{2}+A_{2}{ }^{2}+A_{3}{ }^{2}$ は直流成分, 残りの 3 項がド ップラ周波数変化を表わしているので観測されるドッ プラ周波数は

$$
\begin{aligned}
& f_{d 1}=\frac{\left(\boldsymbol{K}_{2}-\boldsymbol{K}_{1}\right) \cdot \boldsymbol{V}}{2 \pi}=\frac{2 n|\boldsymbol{V}| \cos \psi \sin \theta}{\lambda} \\
& f_{d 2}=\frac{\left(\boldsymbol{K}_{3}-\boldsymbol{K}_{2}\right) \cdot \boldsymbol{V}}{2 \pi}=\frac{2 n|\boldsymbol{V}| \sin (\theta+\psi)}{\lambda} \\
& f_{d 3}=\frac{\left(\boldsymbol{K}_{1}-\boldsymbol{K}_{3}\right) \cdot \boldsymbol{V}}{2 \pi}=\frac{2 n|\boldsymbol{V}| \cos \theta \sin \psi}{\lambda}
\end{aligned}
$$

またてのとき， 3 本の入射光のうちの 2 本の入射光の 組合せで生じる干渉縞の間隔は

$$
\begin{aligned}
& \Delta d_{1}=\lambda /(2 n \sin \theta) \\
& \Delta d_{2}=\lambda /\{2 n \sin (\theta+\psi)\} \\
& \Delta d_{3}=\lambda /(2 n \sin \psi)
\end{aligned}
$$

となっており, 複数の入射光によって同一点に複数の 干渉縞が存在するとき観測されるドップラ周波数はそ れぞれの干渉縞によって生じるドップラ周波数の線形 結合となっているととがわかる. こてでは $I_{1}$ と $I_{2}$, $I_{1}$ と $R_{1}, I_{2}$ と $R_{1}$ によって生じる干渉縞からのドッ プラ周波数がそれぞれ $f_{d 1}, f_{d 2}, f_{d 3}$ となっている.

てれらのととから, 固体表面からの鏡面反射光を測 定体積に再入射させるととにより, 従来のレーザー・ ドップラ速度計測において観測されるドップラ周波数 $f_{d_{1}}$ を表わすスペクトラムのほかに，あらたに二つの 固体表面速度 $|\boldsymbol{V}|$ および固体表面の移動方向 $\psi$ をパ
ラメータとするドップラ周波数 $f_{d 2}, f_{d 3}$ を表わすス ペクトラムが観測されるととがわかる. ゆえに $f_{d 1}$ の ほかに $f_{d 2}, f_{d 3}$ のうちのどちらかの周波数を得るて とにより, 固体表面速度 $|\boldsymbol{V}|$ および固体表面の移動 方向 $\phi$ の值を独立して求めるてとができる，たとえば ドップラ周波数 $f_{d_{1}}, f_{d_{2}}$ が得られる場合には(6.a)， $(6 . b)$ 式を，また $f_{d 1}, f_{d 3}$ が得られる場合には(6.a)， (6. c ) 式を連立して解くことにより固体表面の移動方 向 $\phi$ は次式のように求めることができる.

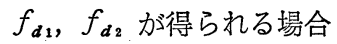

$$
\phi=\tan ^{-1}\left\{\left(\frac{f_{d_{2}}}{f_{d_{1}}}-1\right) \tan \theta\right\}
$$

$f_{d 1}, f_{d 3}$ が得られる場合

$$
\phi=\tan ^{-1}\left(\frac{f_{d s}}{f_{d 1}} \tan \theta\right)
$$

さらに, $f_{d_{1}}$ から光学系の中心軸に垂直な速度成分 $|\boldsymbol{V}| \cos \psi$ が, また $f_{d s}$ から光学系の中心軸方向速度 成分 $|\boldsymbol{V}| \sin \psi$ が次式のように求まるので

$$
\begin{aligned}
& |\boldsymbol{V}| \cos \psi=\frac{\lambda f_{d_{1}}}{2 n \sin \theta} \\
& |\boldsymbol{V}| \sin \psi=\frac{\lambda f_{d \mathbf{s}}}{2 n \cos \theta}
\end{aligned}
$$

固体表面速度を 2 次元速度成分表示することが可能と なる．また，ての式に $\phi$ の值を代入するととにより 固体表面速度 $|\boldsymbol{V}|$ が求まる。

\section{4. 実験}

\section{1 実 験 装 置}

Fig. 3 亿本研究で使用したレーザー・ドップラ速度 計の光学系を示す.レーザー光源 ( $\mathrm{He}-\mathrm{Ne}, 632.8 \mathrm{~nm}$, $15 \mathrm{~mW}$ ) からのレーザー光はビームスプリッタで間隔 $50 \mathrm{~mm}$ の平行で等強度の 2 ビームに分割した後, レン ズ $(f=106 \mathrm{~mm})$ を用いて交差角 $2 \theta=26.53^{\circ}$ で交差 させ測定体積を形成する. 測定対象となる固体表面に はアクリル製回転円盤を用いた．乙の回転円盤表面に 光を入射したときの反射率は $20 \%$ で, 反射光の鏡面

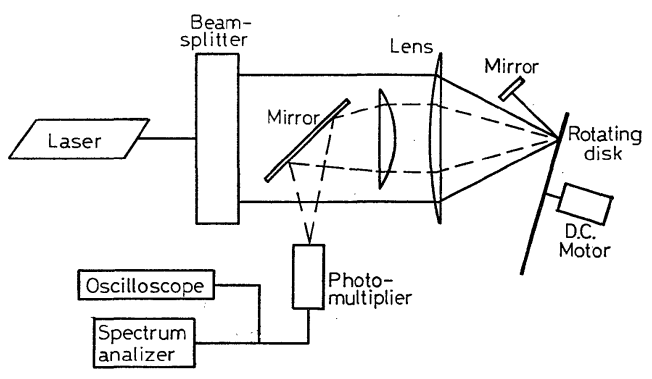

Fig. 3 Optical system of laser Doppler velocimeter 
反射成分 $S$ 之拡散反射成分 $D$ の比は $S / D=3.0$ で ある．回転円盤は D.C.モータで駆動され，任意の回 転速度が選択できる．回転円盤表面からの鏡面反射光 の一方は回転円盤からレーザー光源側 $10 \mathrm{~mm}$ 亿設置 した平面鏡（反射率 85\%）によって再反射される。平 面鏡はこの再反射光か測定体積に入射するように角度 の調整を行う。レーザー光源からの 2 本の入射光と反 射鏡からの再反射光が回転円盤で拡散反射するととに よって生じるドップラ周波数シフトを受けた散乱光 は，レンズで集光されフォトマルチプライヤで光電変 換される。得られた信号はオシロスコープで表示し， スペクトラムアナライザで周波数解析した。

\section{2 実験結果ならびに考察}

Photo. 1 4 は，Fig. 3 の光学系用いて回転円 盤の速度測定を行ったときのスペクトラムアナライザ で観測されるドップラ周波数を示すスペクトラムであ る. 左側の高いピークの中心が零周波数を示してお り, 横軸（周波数目盛）は $2 \mathrm{MHz} /$ Div., 縱軸（ゲイ ン目盛）は $10 \mathrm{~dB} /$ Div., 走査フィルタの帯域幅は 100

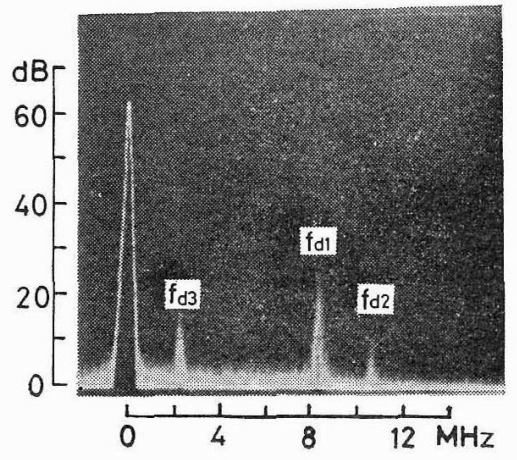

Photo. 1 Doppler frequency spectra obtained by three beams $I_{1}, I_{2}$ and $R_{1}$ where $\psi=4^{\circ}$ and $V=12 \mathrm{~m} / \mathrm{s}$

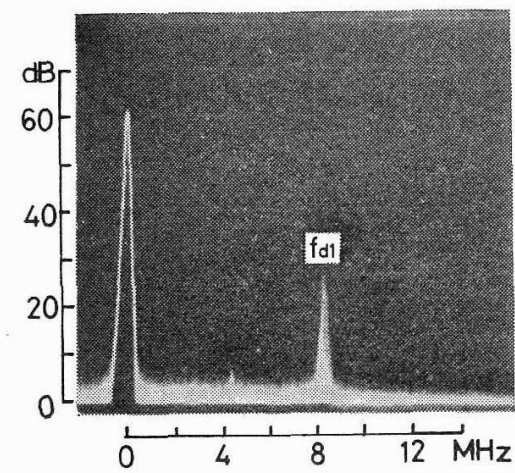

Photo. 2 Doppler frequency spectrum optained by two beams $I_{1}$ and $I_{2}$ where $\psi=4^{\circ}$ and $V=12 \mathrm{~m} / \mathrm{s}$
$\mathrm{kHz}$ ，掃引時間は $20 \mathrm{~ms} /$ Div. である. Photo. 1〜3 は，回転円盤の測定点の速度 $|V|=12 \mathrm{~m} / \mathrm{s}$, 移動方向 $\phi=4^{\circ}$ の同一条件下で観測したスペクトラムである. Photo. 1 は Fig. 3 の光学系を用いたとき観測され るスペクトラムを示している，観則されるスペクトラ ムは $\phi<\theta$ の条件下では(6、a) (6. c) 式办ら $f_{d_{3}}<$ $f_{d 1}<f_{d 2}$ の関係が成立するので，てのスペクトラム図 は左側加零周波数, $f_{d 3}, f_{d 1}, f_{d 2}$ 老表わしている. レーザー光源からの 2 本の入射光によって生じるスぺ クトラム $\left(f_{d_{1}}\right)$ に比べて、レーザー光源からの1本の 入射光と鏡面反射の再反射光によって生じるスペクト ラム $\left(f_{d 2}, f_{d s}\right)$ は，鏡面反射の再反射光の強度が低く なっているため $10 \mathrm{~dB}$ 程度ゲインが低下していること がわかる. Photo. 2 は反射鏡を用いずに测定した場合 でレーザー光源汃らの 2 本の入射光 $I_{1}, I_{2}$ によって 生じるスペクトラム $\left(f_{d_{1}}\right)$ のみか権測されている。乙 れは，通常の 1 次元レーザー・ドップラ速度計測を行 ったとさ得られるスペクトラムである. Photo. 3 は， レーザー光源からの入射光のうち $I_{2}$ を遮断したとき

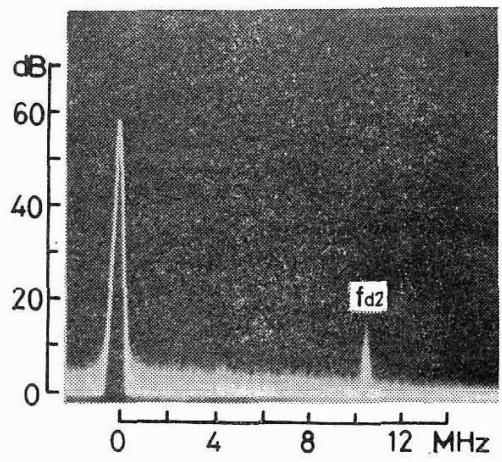

Photo. 3 Doppler frequency spectrum obtained by two beams $I_{2}$ and $R_{1}$ where $\psi=4^{\circ}$ and $V=12 \mathrm{~m} / \mathrm{s}$

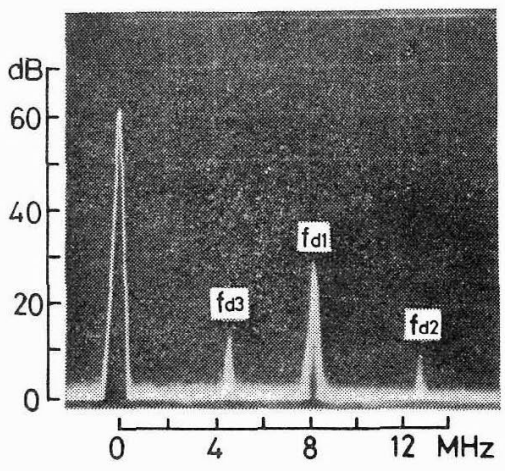

Photo. 4 Doppler frequency spectra obtained by three beams $I_{1}, I_{2}$ and $R_{1}$ where $\psi=8^{\circ}$ and $V=12 \mathrm{~m} / \mathrm{s}$ 
得られるスペクトラムで $I_{1}, R_{1}$ によって生じるスペ クトラム $\left(f_{d_{2}}\right)$ のみが観測されている. Photo. 1〜3 から，本研究で用いた光学系で観測されるドップラ周 波数は，3 本の入射光のうちの 2 本の入射光の組合せ で生じる干渉縞からのドップラ周波数の線形結合とな っているととが確認された. Photo. 4 は, 测定点の 速度を変えずに回転円盤の移動方向 $\phi$ を $\phi=8^{\circ}$ に変 化させたとき観測されるスペクトラムの状態を示して いる. Photo. 1 と Photo. 4 を比較すると, $f_{d_{1}}$ の スペクトラムはほとんど移動していないのにたいして $f_{d 2}, f_{d 3}$ を表わすスペクトラムが移動していることが わかる. Fig. 4〜Fig. 6 は，回転円盤の速度一定で 移動方向を $1^{\circ} \leqq \phi \leqq 10^{\circ}$ の範囲で変化させたときに得

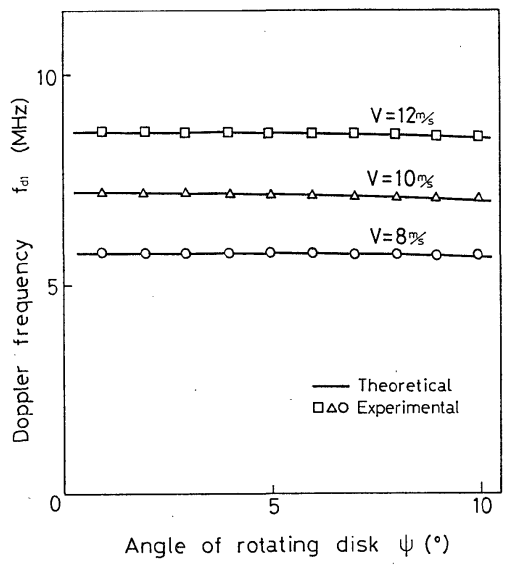

Fig. 4 Relation between angle of rotating disk and the Doppler frequency $f_{d_{1}}$ where the velocity of rotating disk is considered as a parameter

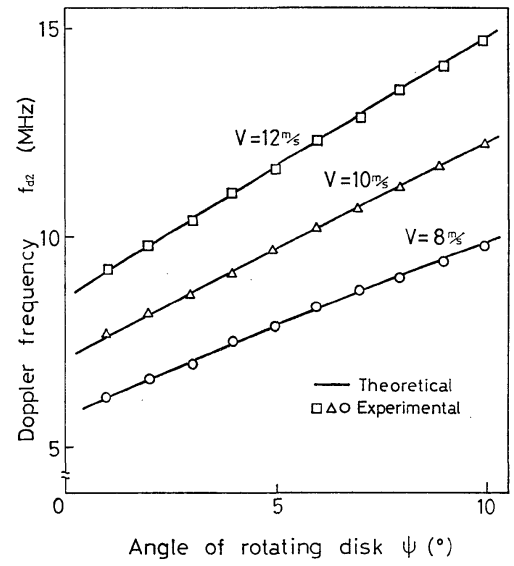

Fig. 5 Relation between angle of rotating disk and the Doppler frequency $f_{d_{2}}$ where the velocity of rotating disk is considered as a parameter
られるスペクトラムの周波数と回転円盤の移動方向の 関係について示したものである.乙れらの図の実線は 理論值を，プロットは実験值を表わしている. Fig. 4 は, 回転円盤の移動方向 $\psi$ とスペクトラムの周波数 $f_{d_{1}}$ の関係を示している. (6. a)式加ら $f_{d_{1}} \propto \cos \psi$ の

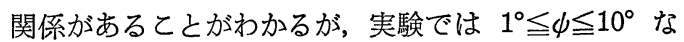
ので $\cos \psi \fallingdotseq 1$ でありスペクトラムの周波数 $f_{d 1}$ の值 に対する $\psi$ の依存度は小さく， $f_{d_{1}}$ はほぼ一定值をと る. Fig. 5, Fig. 6 は, それぞれ回転円盤の移動方向 $\phi$ とスペクトラムの周波数 $f_{d_{2}}, f_{d 3}$ の関係を示してい る. (6. b ) 式加ら $f_{d_{2}} \propto \sin (\theta+\phi),(6 . \mathrm{c})$ 式加ら $f_{d 3}$

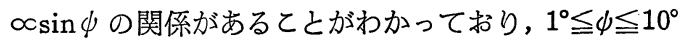
では $f_{d 2}, f_{d 3}$ は $\psi$ の増加にしたがって単調増加する. 各図とあ理論値と実験值はきわめてよく一致してい る.

Fig. 7 は，設定した回転円盤の移動方向とその状

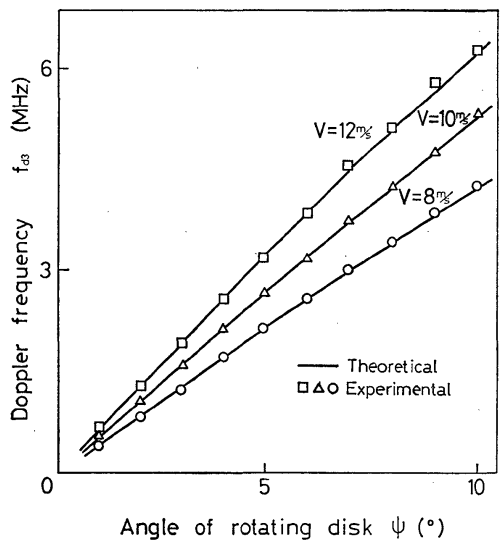

Fig. 6 Relation between angle of rotating disc and the Doppler frequency $f_{d_{3}}$ where the velocity of rotating disk is considered as a parameter

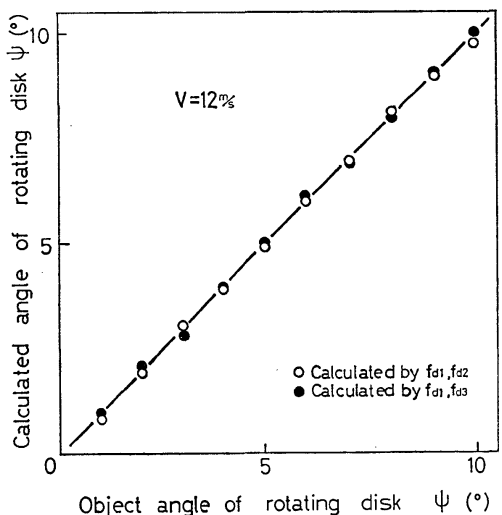

Fig. 7 Linear relation between the object and the calculated angle of rotating disk 


\section{6 昭和 61 年 10 月}

態で回転円盤の測定点の速度 $|\boldsymbol{V}|=12 \mathrm{~m} / \mathrm{s}$ で測定を 行ったときに観測されたスペクトラムの周波数から算 出した回転円盤の移動方向 $\psi$ の関係を示している. ててで白丸は $f_{d 1}, f_{d 2}$ を用いて (8. a) 式から求めた 值を，黒丸は $f_{d 1}, f_{d 3}$ を用いて (8. b ) 式から求めた 値をそれぞれ示している. 両者の間にはよい一致がみ られる.

以上の結果から，固体表面速度計測の際生じる鏡面 反射光を測定体積に再入射するととによって観測され るスペクトラムの周波数から固体表面の移動方向が求 まることが確認された，また，てのとき得られるスぺ クトラムの周波数から(8.a)，(8. b) 式を用いて固体 表面速度を 2 次元速度成分表示するてとが可能とな る. その際得られるのは，入射する 2 本のレーザー光 によって生じる干涉縞に対して垂直な速度成分（光学 軸に対して垂直な速度成分）之光学系の中心軸方向速 度成分の 2 次元方向の速度成分である.

ことで注目すべきことは，本研究の手法を用いるこ とにより光学系の中心軸方向速度成分が測定できると いうことである. なぜなら，従来の光学系による多次 元速度測定は測定体積仙設定方向の異なった干涉縞を 形成するととによって行われるので，固体表面速度計 測の場合, 光学軸方向に対して垂直な 2 次元方向の速 度成分の測定は通常の光学系で測定することは可能で あった. しかし, 光学系の中心軸方向速度成分を測定 するためには干渉縞を光学軸に対して直角に作らなけ ればならないため，レーザー光を光学軸に対して測定 対象の前後から入射しなければならず，不透明な固体 表面の場合は測定できなかった：そのため，光学軸方 向速度成分を測定するためには特殊な構成の光学系が 必要とされ，マイケルソン干涉計を変形して光学系を 形成する方法が報告されているが，ての方法には光学 系構成が複雑であるという難があった. その点, 本研
第 22 巻 第 10 号

究で用いた手法は鏡面反射光が得られる固体表面の速 度計測に応用した場合，きわめて有効である之考えら れる．ただし，今回行った実験は固体表面の移動方向 と観測されるスペクトラムの周波数の関係を調べるた めの基礎的なものであるため, 使用した光学系では固 体表面の移動方向に応じて平面鏡を設定して鏡面反射 光が測定体積に入射するように調整しなければならな い. その点に関しては，反射鏡に凹面鏡を用いること によって，固体表面の移動方向が不明であってあ常に 鏡面反射光が測定体積に戻る光学系が構成できる. 現 在，凹面鏡を用いた，さらに実用的な光学系について 検討を行っており，その結果についての議論は別紙に 譲りたい.

\section{5. まとめ}

本論文ではレーザー・ドップラ速度計を用いた固体 表面速度測定の際生じる鏡面反射光の幾何光学的性質 を利用して固体表面の移動方向を測定し, 固体表面速 度を 2 次元方向成分で表示する方法を示した. さら に，基礎的実験からその妥当性を確認した。

最後に，本研究を進めるにあたって終始協力いただ いた矢野秀幸君に謝意を表する。

\section{参 考 文 献}

1) 中山, 青木, 太田：レーザドップラ速度計の出力信号に 与える諸因子の影響, 計測自動制御学会論文集, 21-3, $284 / 291$ (1985)

2）奈良治郎：表面あらさ，光学的測定ハンドブック（田幸, 辻内, 南編), 601, 朝倉書店 (1981)

3）中谷，山田：レーザを用いた流速測定，システムと制御， 18-8, 453/460 (1974)

4) F. Durst, A. Melling and J.H. Whitelaw: Principles and Practice of Laser-Doppler Anemometry, Academic Press (1976)

5）中谷, ほ加：LDV の基檚之応用, 日刊工業新聞社 (1980) 